\title{
'I'm afraid I have fallen in love with the specialty'
}

Interview by Kate Quinlan

Hira Nazir, 26, is a Dental Core Trainee OMFS at Pinderfields General Hospital in Wakefield. Hira graduated from the University of Manchester in 2014 and is applying to medical school for entry in September 2017, in order to pursue a career in oral and maxillofacial surgery.

W akefield is 11 miles away from where I live in Leeds. It usually takes me 20 minutes to drive to work from my flat. I rent by myself and am fortunate enough to have a good view of Leeds city centre from the 14th floor. I usually have toast for breakfast on the dining table facing the balcony - the most peaceful part of my day! I don't quite have enough time to enjoy my coffee as peacefully so that is drunk in the lift down to the car park.

I was born and brought up in Waldorf, a small village near Frankfurt in Germany, and lived there for 13 years. We then moved to Manchester where my family still live. My father works in a hotel reception in Old Trafford; he has always been a businessman but lost his business in the recession. My mum used to work in a restaurant 15 years ago but had to leave and is now a full-time carer for my autistic brother.

\section{Schedule and duties}

As a DCT OMFS at the hospital we work on a 24-hour on-call rota. The hours and days vary week by week; I did around 72 hours last week. I was covering clinics, theatre and minor oral surgery Monday-Thursday then was on long day on call Friday-Sunday. I am just finishing 30 hours this week which included rest day Monday and Tuesday then back to work Wednesday-Friday. A usual week without on call will be Monday-Friday 48 hours.

We cover two full weeks of on call spread over four weeks (12.5 hour shifts; one week of long days $8 \mathrm{am}-8.30 \mathrm{pm}$ and one week of nights 8 pm- $8.30 \mathrm{am}$ ) and then two weeks are the normal week without on call.
An OMFS trainee's duties are quite vast. We see adults and children here at Pinderfields General Hospital but also cover Dewsbury District Hospital and Pontefract General Infirmary, where we do a clinic and theatre once a week and also cover out of hours OMFS service.

Ward round starts at 8 am with the consultant and registrars/staff grade dentists. We meet in the multi-disciplinary team room and the night, on-call DCT presents and discusses the 'case' with the consultant and the team.

Whilst on ward round we will assess the patient in front of the consultant including doing a full examination which could be cranial nerve testing or chest exam. It is quite a good learning experience as we will often get quizzed and be put on the spot in front of patients!

Any ward jobs such as cannulating, prescribing drugs, drain removal or discharging patients are carried out by the on-call DCT. We will also see a few patients that have been admitted overnight and may need treatment urgently in the morning. The patient will have usually been prepared by the night on-call DCT for the procedure. Here at Pinderfields we receive a lot of fractures, abscesses and wounds that need debriding and closing. Dog bites seem to be quite prevalent here too! A DCT will be responsible for taking this patient to acute theatre and if we feel competent we do the procedure alone, such as closure of lacerations or draining a simple abscess; otherwise we assist and shadow our seniors.

Other duties include clerking in patients for theatre whether that's elective or trauma list. We also scrub in during procedures and

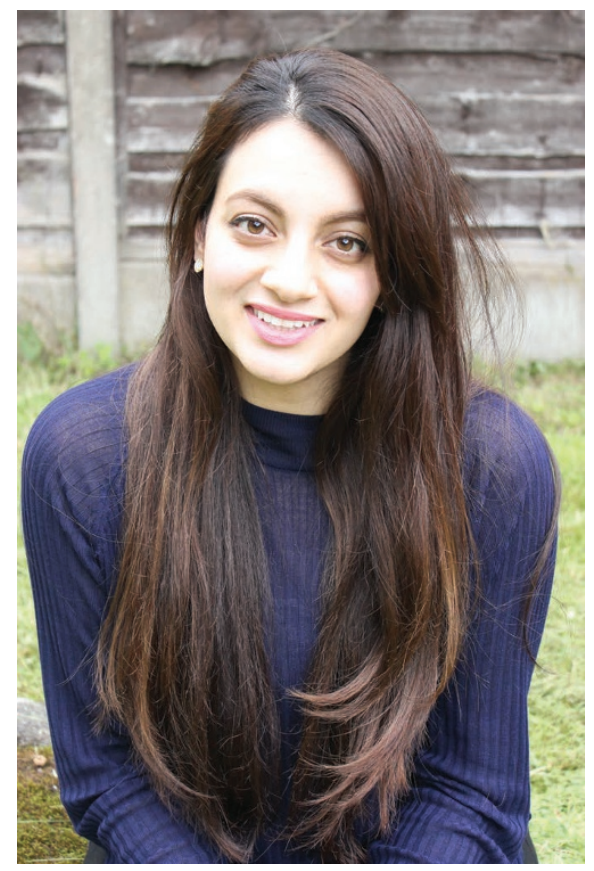

assist or observe. The consultants here are great; they always push us to learn more and will often teach us procedures, like plating a fractured mandible, and let us have a go under supervision.

Other than operating we help run consultant and staff grade clinics, oncology clinic, minor oral surgery, IV sedation and also have a DCT acute clinic to run alongside.

During the clinics we see patients alone and will usually take a history and exam, come up with a differential diagnosis, special investigation and treatment plan.

Out of hours and over the weekend we don't have a registrar onsite as they are based in Leeds General Infirmary. We have a really good relationship with them and work really well as a team.

My DCT1 post here at Pinderfields is 12 months and I finish in two months. I am then starting a DCT2 post at Liverpool Dental Hospital and Aintree University Hospital for 12 months which I am very excited about.

\section{Choosing surgery}

I only studied dentistry to pursue OMFS but throughout my training I was exposed to so many great specialities and I felt comfortable practising dentistry. For me DCT was a tipping point. I was either going to love it or simply leave and never look back.

I am afraid I have fallen in love with the specialty. The learning curve this year 
has been immense: bringing together medicine and dentistry in such a harmonious way whilst being able to use all your practical skills. You are part of a big family, all providing the best service possible for that patient; that patient who is someone's mother, father, sister, daughter or son. That could be my child on the table and I want to do everything I possibly can to help them.

I found it very difficult to secure a DCT post. I didn't have any relatives who were in the field or many friends I could ask for help. It was all a bit of luck as I had to go through second rounds to secure a post for DCT1. Since then, during my second round applying (for a DCT2 post), I have felt so much more prepared and received multiple offers in my first round including my first choice.

There is definitely a way to prepare! A portfolio plays a huge part of the interview process. Ensuring you keep a track of all your treatments, feedback and also certificates is so important. Taking part in audits, local and regional presentations can go a long way to make you stand out.

The other half of the interview involves questions on your clinical knowledge, professionalism and management as well as clinical governance. Keep an eye out for medical interview books as these really helped me to prepare, and practise with your educational supervisor!

\section{A sense of pride}

Ed's note: Hira has a letter published in this issue of the BDJ; see page 51

I do consider myself to come from a lower socioeconomic background. Neither of my parents attended university and if it wasn't for the guidance I had during my college years, I am not sure whether I would've even entered higher education. I never thought it was possible for me.

I was part of the Manchester Access Programme (MAP) which is run by widening participation at the University of Manchester. It helps college students from a lower socioeconomic background enter higher education. Throughout university I was an ambassador for MAP helping other college students by running workshops and mentoring. This gave me a great sense of pride as my mentees were becoming my colleagues and I was giving back to my local community.

It made me realise that I can achieve anything I work towards.

\section{The strike}

I did get involved with the junior doctor/ dentist strike. It is absolutely beyond me how we can possibly work more without jeopardising patient care or the little private time we actually get.

A colleague of mine, a medical registrar, has decided to leave the specialty and go in to general practice training due to the proposed changes. Such a loss to the specialty but I don't blame him.

I know it may appear extreme to do a full walk out but I genuinely believe it was done for the right reasons. It was carefully planned and patients weren't neglected. It was the only way to make our voices heard. Unfortunately, I don't think this is the end to the demonstrations as the contract has been rejected by the BMA [5 July 2016]. I hope we can come to an agreement with the Government so we can all go back to what we are here to do, provide an outstanding service to our patients.

\section{Further education}

In my letter to the $B D J$ [vol. 221 p. 51], I mention having to undertake countless courses. After graduating I don't think many young dentists realise that this isn't actually it. Firstly, MFDS/MJDF have almost become compulsory, especially when applying for DCT.
The hospital has also organised local teaching which is protected time. This is very useful as it is the consultants or registrars/staff grades who will teach us first hand on selected topics and often we can pick too. This could include a wide range of conditions or procedures we undertake or see such as mandibular or mid face trauma and management, salivary gland disease or management of an impacted third molar.

\section{Taking a break}

An average day would consist of 8-12.30 either on clinics, theatre, minor oral surgery etc. Lunch is usually at $12.30-1.30 \mathrm{pm}$ and then work again from 1.30-5 pm. Thursdays if in theatre is usually 'no lunch Thursday' as we have a busy theatre list. Big breakfast Thursdays!

Whilst on call I try to get a break whenever I can really because I never know when it is going to get busy. There will be days I forget to eat and have to constantly remind myself to look after myself first.

If any acute treatment needs doing many of us sacrifice breaks, lunch and stay behind to help; it is all part of the job and teamwork.

I usually try to spend lunch with my fellow DCT colleagues; it gives us a chance to catch up on our recent experience and learn from each other. I will also take some time out to pray in the mosque inside the hospital just

\section{'There is definitely a family feel in the hospital as we spend so much time together. I have made some lifelong friends.'}

Since then I have attended conferences including BDA and BAOMS and will be going to EACMFS in September 2016.

I am currently considering either completing an ALS or ATLS or even an immediate life support course. These are really useful when working in a busy trauma setting. I have been called to resus a number of times whilst working on call or even to a ward patient who has been poorly. There are also numerous courses on head and neck anatomy, basic principles on maxillofacial plating or trauma run by the Royal College of Surgeons or AO Foundation to list but a few.

It is tricky deciding which courses or conferences to attend as it can really be costly. On top of this we have to attend a set number of study days organised by the Deanery thankfully these are free and valuable. before the afternoon sessions start: again another peaceful part of my day.

There is definitely a family feel in the hospital as we spend so much time together. I go for meals regularly with my colleagues and also with my seniors outside of work. I have made some lifelong friends.

It is easy to become isolated especially if I am doing a long block of nights and then have time off for recovery but I do appreciate those times as it allows me to take a step back and reflect.

There is also a bit of a competitive atmosphere between us DCTs but it allows us to develop to the best of our abilities.

\section{Support}

My educational supervisor, an OMFS consultant, has been brilliant and has pushed 
me in the right direction. We meet regularly for meetings and to catch up on my personal academic goals. He is extensively involved in charity work in Nepal which I really admire.

I have also been lucky enough to have a mentor type figure: an associate specialist in OMFS. He has treated me like family. Working in hospital is really character building and it is so important to have supportive seniors that will guide you carefully.

We had a week of induction when we started and the staff grades and registrars were brilliant at easing us in. Of course it is daunting doing an on call alone out of hours and I remember being the first DCT on call; within the first few hours I had to call my consultant in for a patient with an airway concern who we had to manage in the resuscitation area of the emergency department.

Working in hospital has really developed me clinically but also personally.

\section{Down time}

On a normal working day, I get home from work around 6 pm. I make myself dinner, catch up with family and friends and try to make time for gym. I love swimming and find this very relaxing, especially when I struggle to switch off from a hard day at work.

It is very challenging to find the right balance between work and home/personal life. It took me six months to figure out that balance. I have learnt so much about time management and prioritising. It is a skill in itself.

I often have a little work to do at home whether that's bedtime reading for a procedure the following day, something I have learnt the same day or working on an audit/research project.

If I am on call, I get home around either 9 am or pm depending on whether I have been on long days or nights; I usually just eat and sleep.

I have managed to book annual leave for most of this summer and will be going abroad with some friends. I really need this holiday before I burn out. I have worked hard in the last ten months.

\section{Long term}

Leeds is a lovely city but long term I would like to move back to Manchester. Realistically I will need all the support I can get from my family if I am planning to have my own family and pursue a career in OMFS.

I have made the right career choice. I am glad I am skilled manually and able to undertake so many procedures independently. It has also opened up so many doors for me. Dentistry is so much more than people perceive.

Dentistry is still thought of as a secure career pathway and having come from a working class background it is very reassuring to know I will be able to provide for my family regardless.

I would strongly encourage every dental student to consider a placement in OMFS. It has made me a better dentist. I feel so much more confident treatment planning and treating medically compromised patients. With an ageing population, this is so important and a challenge every dentist will have to face. OMFS has allowed me to understand and see firsthand the bigger picture of a patient's pathway in to secondary care. I have seen the extremes of appropriate referrals and also patients that require immediate life-saving treatment.

My philosophy is to have one learning point a day otherwise I've wasted the day. So far I've not wasted a single day. 